\title{
The Visual and Spectrophotometric Effect of External Bleaching on OMNiCHROMA Resin Composite and Natural Teeth
}

\author{
Michael Brian Evans \\ West Virginia University, mevans11@mix.wvu.edu
}

Follow this and additional works at: https://researchrepository.wvu.edu/etd

Part of the Dental Materials Commons, and the Prosthodontics and Prosthodontology Commons

\section{Recommended Citation \\ Evans, Michael Brian, "The Visual and Spectrophotometric Effect of External Bleaching on OMNiCHROMA Resin Composite and Natural Teeth" (2020). Graduate Theses, Dissertations, and Problem Reports. 7619. https://researchrepository.wvu.edu/etd/7619}

This Thesis is protected by copyright and/or related rights. It has been brought to you by the The Research Repository @ WVU with permission from the rights-holder(s). You are free to use this Thesis in any way that is permitted by the copyright and related rights legislation that applies to your use. For other uses you must obtain permission from the rights-holder(s) directly, unless additional rights are indicated by a Creative Commons license in the record and/ or on the work itself. This Thesis has been accepted for inclusion in WVU Graduate Theses, Dissertations, and Problem Reports collection by an authorized administrator of The Research Repository @ WVU. For more information, please contact researchrepository@mail.wvu.edu. 
The Visual and Spectrophotometric Effect of External Bleaching on OMNiCHROMA Resin Composite and Natural Teeth

\title{
Michael B Evans, D.D.S.
}

Thesis Submitted to the

School of Dentistry

At West Virginia University

In Partial fulfillment of the requirements

For the degree of

Master of Science In Prosthodontics

Matthew Bryington, DMD, MS, FACP (Chair)

Bryan Dye DDS, MS, FACP

Bryan Weaver, MD, DDS

\author{
Department of Restorative Dentistry \\ Morgantown, West Virginia
}

2020

Keywords - OMNiCHROMA, Bleaching, Vital tooth bleaching, Colorimeter, Shade Comparison 


\begin{abstract}
The Visual and Spectrophotometric Effect of External Bleaching on OMNiCHROMA Resin Composite and Natural Teeth

Michael Evans, D.D.S.
\end{abstract}

Objective: To determine the visual and spectrophotometric effect external tooth bleaching has on natural tooth structure and OMNiCHROMA composite at various number of treatments. Variables were compared to determine if there is a detectable difference between the composite and the tooth before and after bleaching.

Methods: Preparation and restoration of 25 previously extracted teeth was completed. OMNiCHROMA composite was used. Each tooth was measured visually with a VITA shade guide and a colorimeter. Measurements were recorded before bleaching, after 5 and 10 treatments. Statistical analysis was completed and $\Delta \mathrm{E}$ values between the composite and tooth were compared between the 3 treatment intervals.

Results: $\Delta \mathrm{E}$ values were significantly different between the 0 and 10 treatment groups but not significantly different from the 0 to 5 treatment groups. The tooth/composite $\Delta E$ was significantly lower at 10 treatments than at 5 and 0 treatments. The mean $\Delta E$ was greater for the tooth than the composite at 5 treatments and 10 treatments. When compared using the visual shade guide, on average, a larger number of shade changes were noted in the tooth compared to the composite at 5 and 10 treatments.

Conclusions: In the present study, there was a significant decrease in the $\Delta \mathrm{E}$ value from 0 to 10 treatments. This indicates that the shade difference between the composite and the tooth decreases as the tooth becomes brighter. The composite demonstrated the ability to change shade as the surrounding tooth structure became brighter - both visually and with the use of the colorimeter. 


\section{Table of Contents}

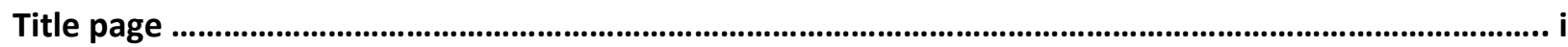

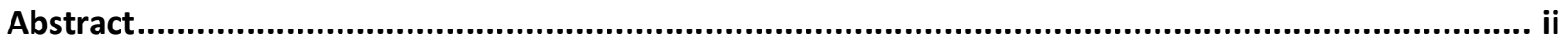

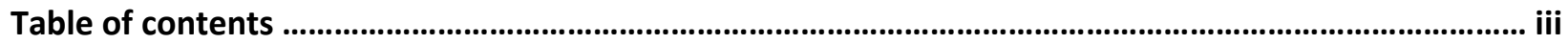

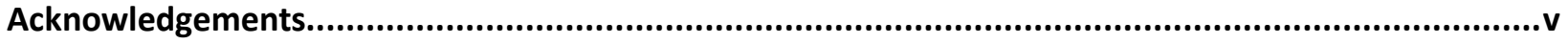

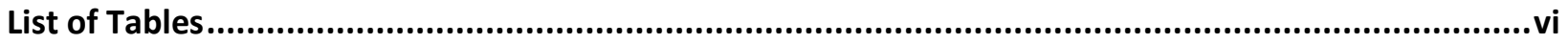

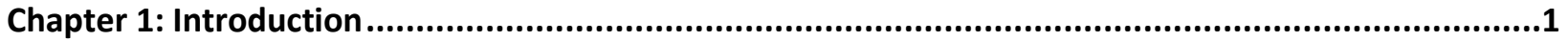

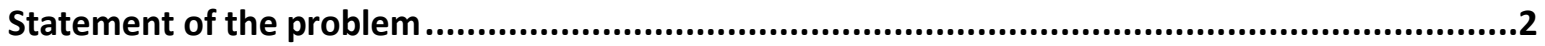

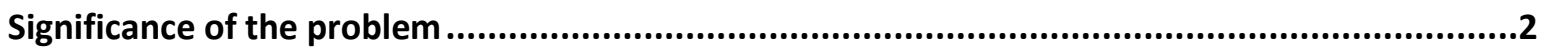

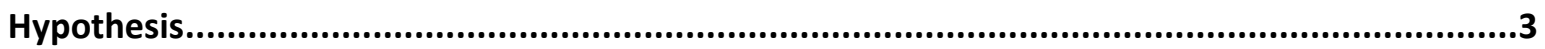

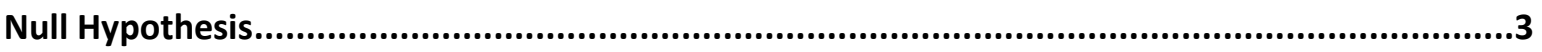

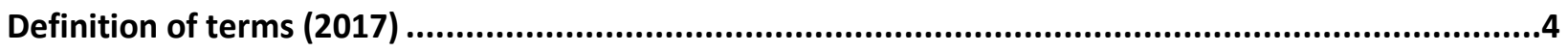

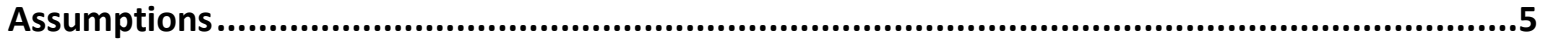

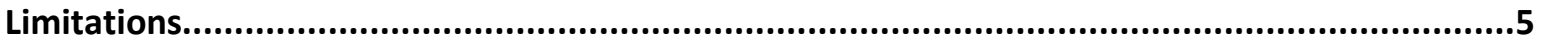

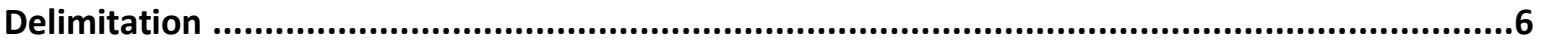

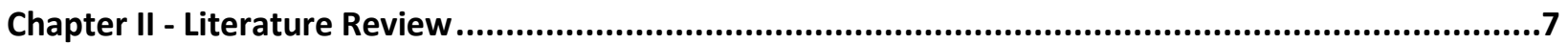

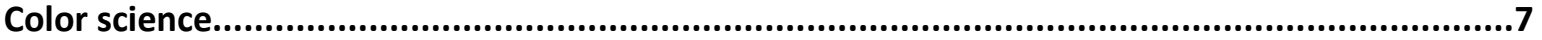

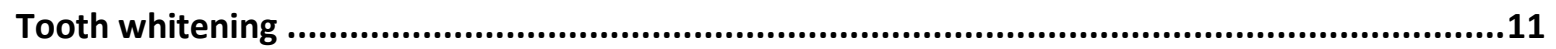

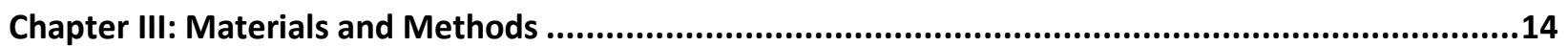

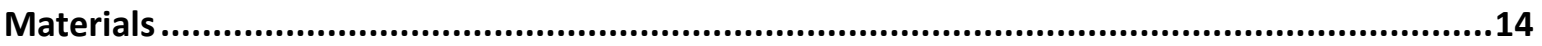

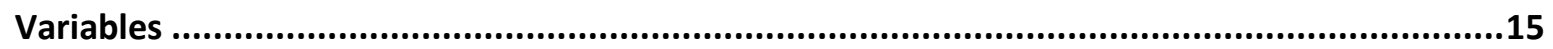

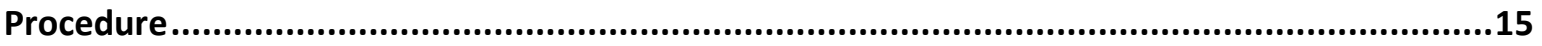




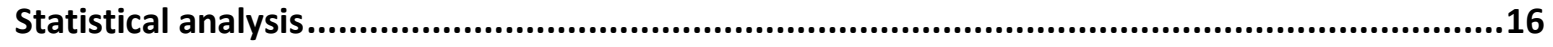

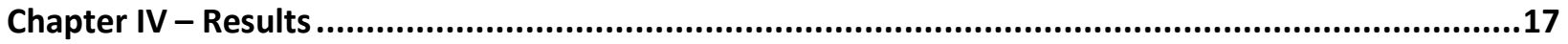

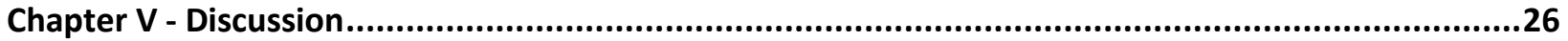

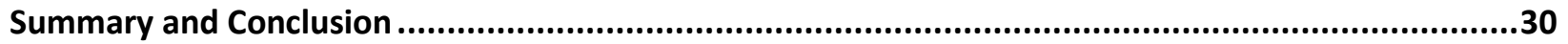

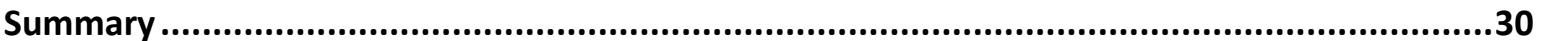

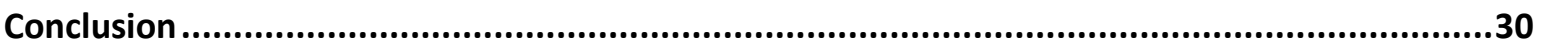

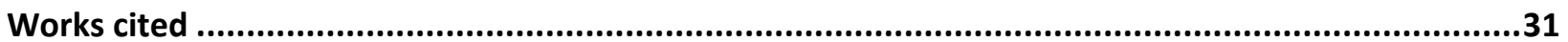




\section{Acknowledgements}

I would like to thank the following for their guidance and contributions

Dr Matthew Bryington - I am thankful for the instruction and guidance you provided with this project

Dr's Ben Kordusky, Caitlin Libby and Vivia Sequeira - Thank you all for helping me acquire needed materials for this study to be completed

Dr Matthew Harper - Thank you for your guidance with writing and completing this thesis project and providing information of important steps and important dates

Dr. Gerry Hobbs - The help you provided with statically analysis and interpretation of the data was invaluable and very appreciated

Dr Elizabeth Gao - Thank you for allowing me to use your VITA Easyshade as this was vital to the study and would not have been possible without it

Dr Fotinos Panagakos, Charles Wisser and Christopher Braham - Thank you for helping provide me a place to safely and efficiently work at the HSC due to the closure of Suncrest Town Center due to the ongoing pandemic 


\section{List of Tables}

Table $1-L, A$ and $B$ values

Table $2-\Delta \mathrm{E}$ of composite and tooth at 0 and 5 treatments

Table $3-\Delta \mathrm{E}$ of composite and tooth at 0 and 10 treatments

Table 4 $-\Delta E$ of composite/tooth on each tooth at 0,5 and 10 treatments

Table 5 - VITA classic shade of tooth or composite at 0, 5 and 10 treatments

Table 6 - shade tab changes of tooth and composite at 0 to 5 and 0 to 10 treatments 


\section{Chapter 1: Introduction}

Achieving optimal esthetics in restorative dentistry is a difficult task to complete. Resin composites are used with direct techniques to restore tooth-like appearance and structure in order to recreate a healthy and esthetically pleasing result. Dental trauma, poor oral hygiene resulting in the presence of caries, and congenitally missing or misshapen teeth are the most common reasons for the placement of resin composite restorations (Çetin and Erdal Eroğlu 2019).

One common issue that has persisted throughout the use of composite restorations in direct dentistry is the difficulty of recreating proper shade, texture, and translucency of the missing or damaged dental structure. With respect to correctly matching the shade, there are a plethora of techniques and methods to aid the clinician. Whatever the technique used to match the surrounding dentition, the resin composite has inherent physical and chemical properties that contribute to its appearance. A vast amount or research and development by manufacturers has been done to make these materials color stable over time (Suh et al. 2017). The shade of teeth is subject to change over time. A person with multiple restorations in the esthetic zone, can appreciate subtle changes in the remaining tooth structure that does not occur in the resin composite. The common procedure of 'teeth whitening' can drastically brighten the natural dentition but provide no whitening benefit of the surrounding dental restorations (Pereira Sanchez, Powers and Paravina 2019).

There have been efforts to create a dental material that more closely mimics the surrounding healthy tooth in color. OMNiCHROMA resin composite is one such material that 
has been created to better match natural tooth shades and is manufactured in Japan by Tokuyama Dental America Inc. This material is available in only one shade and aims to match any surrounding shade once the material is placed and cured. With the popularity of teeth whitening and the common desire for an esthetically pleasing smile, there is a shortage in the amount of literature available regarding the use of this material in conjunction with teeth whitening techniques.

\section{Statement of the problem}

This research intended to explore the effects of dentist-provided, at-home tooth whitening on teeth that were restored using OMNiCHROMA resin composite.

Specific Aim 1: to examine the visual difference that tooth whitening has on the natural tooth structure and the resin composite using standard shade tabs

Specific Aim 2: to examine the quantitative difference that tooth whitening has on the natural tooth structure and the resin composite using a colorimeter (VITA Easyshade Advanced 4.0)

\section{Significance of the problem}

There are many variables that complicate how fast and to what degree one's teeth change in color over time. The patient's desire for an esthetically pleasing smile with minimal polychromic changes is not expected to decline. The use of a dental material that can limit these changes and can blend into the surrounding tooth structure is one that is increasing in popularity. If such a material exists, understanding if this material can predictably maintain its camouflage effect before, during and after teeth whitening procedures is of particular importance when selecting a material to use when restoring a natural tooth. 


\section{Hypothesis}

Hypothesis 1 - when using a visual shade guide, there will be a significant difference in the perceived shade of resin composite before and after bleaching

Hypothesis 2 - when using a colorimeter, there will be a significant difference in the shade of resin composite before and after bleaching

Hypothesis 3 - there will be a significant difference in the $\Delta \mathrm{E}$ of the resin composite and the surrounding tooth structure as bleaching treatment increases from 0 to 10 treatments

\section{Null Hypothesis}

There will be no visibly measurable change in the resin composite shade after whitening gel is applied. There will be no detectable change in resin composite shade after whitening gel is applied when using the colorimeter. The $\Delta E$ value between the composite and surrounding tooth structure will not change as bleaching treatment increases from 0 to 10 treatments. 


\section{Definition of terms (2017)}

CIE LAB system - CIE LAB relates the tristimulus values to a color space; this scale accounts for the illuminant and the observer; by establishing a uniform color scale, color measurements can be compared and movements in color space defined

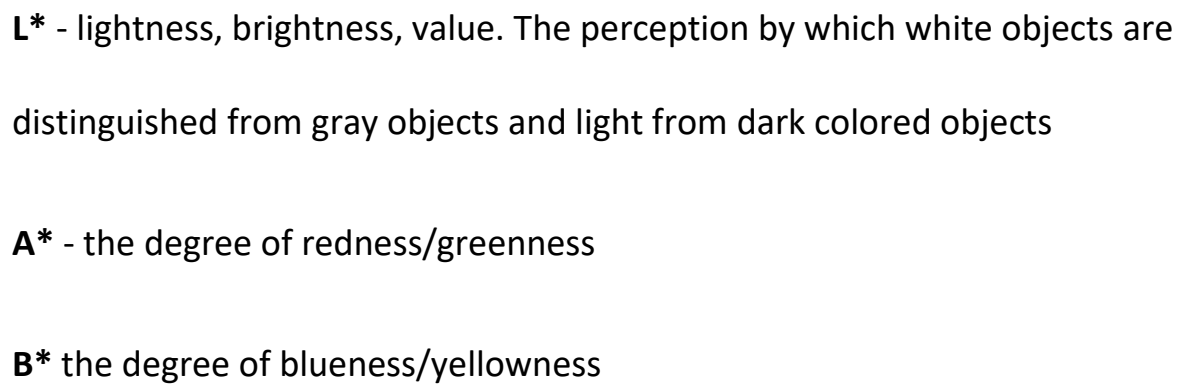

Chroma - the purity of a color, or its departure from white or gray; chroma describes the strength or saturation of the hue

Color - the quality of an object or substance with respect to light reflected or transmitted by it. Color is usually determined visually by measurement of hue, saturation, and luminous reflectance of the reflected light.

Colorimeter - a device that analyzes color by measuring it in terms of a standard color, scale of colors, or certain primary colors; an instrument used to measure light reflected or transmitted by a specimen

Hue - often referred to as the basic color, hue is the quality of sensation according to which an observer is aware of the varying wavelengths of radiant energy; the attribute of color by means of which a color is perceived to be red, yellow, green, blue, purple, etc. White, black, and grays possess no hue

Opacity - The property of a material to hide what is behind it 
Shade - a term used to describe a particular hue, or variation of a primary hue, such as a greenish shade of yellow.

Tooth whitening - the application of an agent (a form of peroxide) or abrasive to the surface of the tooth for beautifying (stain removal), enhancing esthetics, or altering the appearance

Translucency - the property of a material by which a major portion of the transmitted light undergoes scattering

Transparency - the property of a material by which a negligible portion of the transmitted light undergoes scattering

Value - the quality by which a light color is distinguished from a dark color, the dimension of a color that denotes relative blackness or whiteness. Value is the only dimension of color that may exist alone

\section{Assumptions}

1. It is assumed that the same amount of bleaching gel is used each time.

2. It is assumed that all ambient light conditions were the same throughout the experiment.

3. It is assumed that the colorimeter maintained calibration through multiple uses.

\section{Limitations}

1. All work performed was in vitro and thus results could vary from in vivo results.

2. Only one tooth whitening treatment modality analyzed (at-home bleaching).

3. Long term effects (regression) were unable to be documents within the limits of this study. 


\section{Delimitation}

1. This study is limited to one tooth whitening treatment modality (at-home bleaching).

2. This study is limited to only class $V$ restorations.

3. This study is limited to one concentration of whitening gel (15\%). 


\section{Chapter II - Literature Review}

Color science

The theory and study of color in the dental field has transformed throughout time with the aid of technology. Still today, the most commonly preferred color selection method is the visual technique which involves the subjective selection of a template that best matches the intended specimen (Vanderburgt 1990). However, portable and quickly accessible colorimeters have enabled dentists to quickly select a shade of the surrounding dentition in order to select an appropriate shade for the future restoration (Kim-Pusateri et al. 2009). Both the visual technique and the use of a colorimeter uses the principles of hue, value, and chroma in order to match a shade correctly.

There are multiple factors that come into play when analyzing the color of a tooth in order to match it to the surrounding dentition. Ambient lighting, texture, eye fatigue, and translucency of material are some examples of variables to consider when shade matching (Revilla-León et al. 2019). Natural teeth have characteristics that can influence how light is reflected, absorbed or scattered from its surface (Ilie and Furtos 2020). This layering effect is caused by the varying translucency of the enamel layer and the opacity of the dentin layer (KimPusateri et al. 2009).

One of the most rudimentary methods to describe color is the Munsell color system. Created in the early 1900's, Professor Albert Munsell first developed this color system for soil. This was the first known system that separated hue, value, and chroma in a 3 dimensional space (Cochrane 2014). Within the Munsell system, this value is measured vertically on a 0-10 scale (black to white respectively). The chroma value is measured radially from the center of 
the space, outward. This value ranges from 0 to 12 with the 0 -end representing a low chroma grey color and a 12 representing a vivid high-chroma color of the corresponding hue and value. The hue itself is measured by degrees around horizontal circles at a corresponding value and chroma. Hue is divided into 5 principle hues of red, yellow, green, blue and purple (Cochrane 2014).

In order to quantify the color of something and allow for a universal color space, CIELAB color space was introduced in 1976. A numerical value to each color component was created and is known as an L*a*b* score(Kuehni 1976, Kuehni and Marcus 1979). This color space defines colors in three dimensions associated with three attributes of color. The first is value and it is best described as the lightness or darkness of a material and is ranged from 0 (black) to 100 (white); this is the $L^{*}$ variable. The $a^{*}$ variable is a representation of the red/green component and the $b^{*}$ variable is a representation of the yellow/blue component. Both of these variables range from -128 to 128 (Joiner and Luo 2017).

Delta $E(\Delta E)$ is a variable that is commonly used to measure the difference in color for two specimens. Soon after the introduction of the CIELAB color space and $\Delta E$ calculations, instruments like colorimeters and spectrophotometers were developed to measure color and color differences. The use of these instruments have not been universally utilized due to the appearance of an object being highly dependent on the shape, translucency, opacity, and fluorescence of an object (Vichi et al. 2011). The equation used to calculate color differences is

$$
\Delta \mathrm{E}_{*}=[(\Delta \mathrm{L} *) 2+(\mathrm{A} *) 2+(\Delta \mathrm{b} *) 2] 1 / 2
$$


When measuring $\Delta \mathrm{E}$, it becomes important to determine the ability of the human eye to detect a difference and to determine if that difference is clinically relevant. Detecting variations in color can be viewed as a combination of human eye capabilities and skill of the operator and it is accepted that a $\Delta \mathrm{E}$ value less than 1.2 is not predictably detectable by the human eye. A $\Delta \mathrm{E}$ of greater than 1.2 but less than 3.3 are considered detectable by a skilled clinician and a $\Delta \mathrm{E}$ value of greater than 3.3 are detectable by an untrained eye (Vichi et al. 2011). 1.2 is considered the 50:50\% perceptibility threshold. This means that half of clinicians can detect a difference in two colors while the other half cannot (Trifkovic, Powers and Paravina 2018).

To create an esthetically successful composite restoration, one must consider the shade of the tooth, the surface texture of the adjacent teeth, the translucency of the surrounding healthy tooth structure but also the physical properties of the restorative material itself (Tabatabaian 2019). It has been documented that unless the size of the restoration is too large, a patient's ability to discern the color difference between the resin composite and the tooth is less compared to before the restoration was placed (Suh et al. 2017, Samorodnitzky-Naveh et al. 2010). This "blending effect" is a phenomenon that increases as two similar colors become closer and becomes more effective in smaller restorations and when the translucency is greater (Suh et al. 2017).

A dental composite is typically made of an organic resin-based polymer, an inorganic filler and other additives for color, strength and stability of material (Ilie and Hickel 2011). The filler portion of a dental composite is responsible for wear resistance, material strength, and optical properties of the restorative material. It is common for dental composites to be categorized by the filler type and the size. Some composites have particle sizes ranging from 5- 
10 micrometers while others have particle sizes of 20-70 nanometers. The filler also varies in shape as well. Some are spherical and identical while others have a less uniform polygonal shape (Howard et al. 2010).

OMNiCHROMA resin composite is a material that utilizes the previously described principle of the blending effect due to the spherical filler particle size. Its composition is $68 \%$ filler by volume and the filler is composed of SiO2-ZrO2. The $260 \mathrm{~nm}$ spherical filler size and shape allow ambient light to pass through the material and alter the red-to-yellow color spectrum in addition to combined reflected colors of the surrounding dentition. This affords the clinician the ability to use one material to correctly match the shade of many different teeth (Pereira Sanchez et al. 2019). The $260 \mathrm{~nm}$ particle size is very specific to the materials ability to shade-match with such accuracy. Larger or more irregular shaped filler particles can yield a different color which would reduce the composite's ability to match many underlying tooth shades.

Color adjustment potential (CAP) is a term that is used to describe and quantify the interaction of two components: CAP-V, which is visually assessed and CAP-I, which is assessed using a color measuring instrument. CAP-V represents the perceptual aspect of a material and CAP-I represents the physical properties of a material. This data uses $\Delta \mathrm{E}$ values to further quantify the ability of a dental material to blend with its surrounding structure (Trifkovic et al. 2018). Thus, materials with a high CAP can reduce the color differences $(\Delta E)$ and improve the esthetic appearance of a restoration and make it easier for the clinician to compensate for color mismatch (Pereira Sanchez et al. 2019). 


\section{Tooth whitening}

Tooth whitening is one of the most requested cosmetic dental procedure by patients who desire a more esthetic smile (Baroudi and Hassan 2014). There are various methods of whitening procedures but all have the intended goal of a whiter smile. The cause of tooth discoloration is multifactorial and has been grouped into two broad categories. The first type of tooth discoloration is extrinsic discoloration. This type of stain is associated with drinking coffee, red wine, use of tobacco, and other food/drink that can discolor the mouth. In other words, these types of stains are only from external sources that leave behind stains on the teeth. The second category of tooth discoloration is intrinsic stains. These are due to systemic conditions during development, use of certain medications during development, trauma, and some childhood diseases. There are various mechanisms that cause these types of stains but they all involve deformation of the internal tooth structure which results in an altered refractory of light within the tooth which appears discolored (Baroudi and Hassan 2014).

Whitening procedures are most effective against extrinsic stains and have little effect on intrinsic stains while most intrinsic stains are best corrected with direct or indirect restorations (Sun et al. 2011, Hayward, Osman and Grobler 2012). The use of direct and indirect restorations most often involves a reduction of tooth structure and is viewed as a more invasive technique than vital tooth bleaching. Tooth bleaching is not only more conservative than the previously mentioned methods, but it often costs less and is well accepted to be safe and effective (Sun et al. 2011).

There are multiple treatment modalities available for tooth whitening. A widely utilized treatment for whitening is whitening toothpaste. While there are vastly different compositions 
and concentrations of regular and whitening toothpastes available, it has been observed that when compared to using regular toothpaste, brushing with a whitening toothpaste does result in a significant reduction of tooth surface stains (Soeteman et al. 2018). Thus, patients with naturally occurring extrinsic tooth surface discolorations can benefit from the use of whitening toothpaste for removal or reduction of those specific type of stains.

Dentist prescribed, at-home bleaching is often done with a low concentration of hydrogen peroxide (4\%-8\%) or carbamide peroxide (10\%-22\%) gel in a professionally made custom tray where the patient wears this from 2-8 hours per day. Treatment times vary but most take about 2 to 6 weeks to complete treatment (Sun et al. 2011). While positive results can be obtained via this mode of treatment, patient compliance is often a concern. Additionally, this type of treatment yields slower results which should be addressed with the patient before treatment and can ultimately dissuade a patient from this particular treatment modality.

In-office bleaching is a treatment option that can bypass the negative aspects of inhome bleaching treatments. The concentration of the hydrogen peroxide gel used generally varies from $15 \%$ to $40 \%$. The procedure itself is considered minimally invasive as there is no removal of tooth structure like there is with direct or indirect restorations. In addition, the results are immediately visible to the operator and more importantly, the patient (Sun et al. 2011).

An additional treatment modality of note would be over-the-counter bleaching. Often at a concentration of $\sim 5 \%$ hydrogen peroxide, whitening strips can be applied directly to the teeth multiple times per day in order to achieve the desired effect of tooth whitening. This can be an 
acceptable alternative to the professionally made tray but the concentration of the gel is less than professionally prescribed solutions (Soeteman et al. 2018).

Efficacy of tooth whitening procedures varies because diffusion of the product used is dictated by the concentration and the application time (Dietschi, Benbachir and Krejci 2010). It has been demonstrated by numerous studies that the treatment modalities of self-directed athome bleaching strips, professionally prescribed at home bleaching gel/trays and in-office bleaching produce a similar effect on enamel. There have been indications where home bleaching has been shown to be more effective at penetrating into the dentin so this treatment modality can be more effective for intrinsic stains (Dietschi et al. 2010).

By far, the most common complication seen with external tooth bleaching is tooth sensitivity but most systems now have topical agents or additives to reduce sensitivity (Tam, Kim and De Souza 2017). Another concern is that the bleaching agents may weaken the enamel structure making the tooth more susceptible to microfractures and bulk fracture. It should be noted though that further investigation into this issue needs to occur in order to legitimize these concerns (Tam et al. 2017). 


\section{Chapter III: Materials and Methods}

Materials

Twenty-five previously extracted teeth were used for this experiment. The selected

teeth were grossly intact without fracture or caries. Each tooth was autoclaved in a solution of glycerin (Equate, Wal-Mart Stores Inc. AK, USA) and distilled water. Each tooth was placed in a specific compartment within a Plano 3700 utility box (Plano, CT, USA) throughout the duration of the experiment. A 330 carbide bur and 8379F fine football diamond bur were used to prepare a cavity in each tooth and smooth the resulting restoration (Brassler USA Dental Instrumentation, USA). Additionally, Jiffy polishers were used to finish and polish the restoration once cured (Brassler USA Dental Instrumentation, USA). 35\% phosphoric acid (Ultradent, USA ) and Prime \& Bond NT (Dentsply Sirona, NC, USA) was applied to the tooth per manufacturer's instructions. OMNiCHROMA composite resin (Tokuyama Dental, Japan) was used to restore the cavity preparation. A VALO corded LED curing light (Ultradent, USA) was used to cure each composite for the manufacturer's recommendation of 20 seconds.

Opalescence whitening gel (Ultradent, USA) was applied to half of the tooth/composite restoration. Vaseline (Unilever, USA) was placed on the other half to prevent bleaching of this side and to maintain a control. The concentration of the gel was $15 \%$. Saran wrap (S. C Johnson \& Son, USA) was used to cover the tooth once the gel was in place. A VITA classical tooth shade guide (VITA North America, USA) was used for visual shade matching by a single interpreter and a VITA Easyshade Advance 4.0 (VITA North America, USA) was used for spectrophotometric shade matching. Data was entered into Microsoft Excel (Microsoft Corporation, WA, USA). 


\section{Variables}

The variable of $\Delta \mathrm{E}$ was calculated through the following equation.

$$
\Delta \mathrm{E}_{*}=[(\Delta \mathrm{L} *) 2+(\Delta \mathrm{a} *) 2+(\Delta \mathrm{b} *) 2] 1 / 2
$$

Each tooth was measured with the visual tooth shade guide before treatment, at 5 treatments and at 10 treatments.

\section{Procedure}

Principles used in(Braun, Jepsen and Krause 2007)were used to aid in the study design. 25 teeth were selected and placed into a numbered slot, in a Plano 3700 utility box. The teeth were randomly selected from a large group of non-carious and non-fractured teeth that had been previously autoclaved. Each tooth was immersed in a $50 \%$ glycerin $/ 50 \%$ distilled water solution throughout the experiment and was only removed for preparation and placed immediately back in solution. To mimic a standard class $v$ carious lesion, a preparation measuring $2.0 \mathrm{~mm}$ in occlusion-gingival height, $3.0 \mathrm{~mm}$ bucco-lingually and $1.5 \mathrm{~mm}$ axially, was made using a 330-carbide bur. 35\% phosphoric acid was used to selectively etch the enamel and rinsed off after 15 seconds. The light-cured self-priming adhesive was scrubbed onto the prep and cured for 10 seconds. OMNiCHROMA composite resin was then placed and shaped into the prepared site and cured for 20 seconds. The composite was then smoothed with an $8379 \mathrm{~F}$ football finishing bur. The restoration was polished with jiffy points starting with the coarse adjustment point, progressing to the fine and extra-fine polishing points. Visual shade matching of each tooth was completed with the VITA shade guide. Shade of the composite restoration itself was recorded as well as the shade of the natural tooth. VITA Easyshade 4.0 was used to measure the shade of the composite restoration and the shade of the natural 
tooth. L, A and B results for each reading was recorded as well as the corresponding shade tab. $15 \%$ carbamide peroxide Opalescence gel was placed on each tooth then promptly wrapped in saran wrap and placed back in its respective compartment. Whitening gel was removed 6 hours after application, per manufacturer's instructions. In the same manner as before, shade was recorded after 5 treatments and after 10 treatments.

\section{Statistical analysis}

Statistical analyses were performed using JMP (SAS Institute, NC, USA). Shades from the vita shade guide were assigned a 1-16 numerical value and shades were compared between treatment groups using a paired 2 sample t-test. $\Delta \mathrm{E}$ value of the composite on each tooth was calculated from 0 to 5 and 0 to 10 treatments. $\Delta E$ value of tooth was calculated from 0 to 5 and 0 to 10 treatments. The $\Delta \mathrm{E}$ of the tooth and composite on each tooth was calculated at 0,5 and 10 treatment intervals. $\Delta E$ values from each treatment interval were compared using a paired 2 sample t-test. A one factor ANOVA, with $\triangle E$ as the outcome, was used to analyze differences between the composite/tooth $\Delta \mathrm{E}$ at each treatment interval $(0,5$ and 10). Treatment interval of 0,5 and 10 were the variables used and the sampled tooth was a confounder. The factor of interest was the treatment interval. $95 \%$ confidence interval was used for each test ( $\alpha=0.05)$. 


\section{Chapter IV - Results}

\begin{tabular}{|c|c|c|c|c|c|c|c|c|c|}
\hline Tooth & Site & $\begin{array}{c}\text { No } \\
\text { treatment }\end{array}$ & $\begin{array}{c}5 \\
\text { Treatments }\end{array}$ & $\begin{array}{c}10 \\
\text { Treatments }\end{array}$ & 7 & Comp L & 68.90 & 72.60 & 74.70 \\
\hline \multirow[t]{6}{*}{1} & Comp L & 80.50 & 82.80 & 86.10 & & Comp A & -0.80 & -1.70 & -2.90 \\
\hline & Comp A & -1.60 & -2.50 & -2.80 & & Comp B & 14.20 & 15.40 & 14.40 \\
\hline & Comp B & 17.80 & 16.60 & 16.50 & & Tooth L & 70.40 & 75.70 & 77.70 \\
\hline & Tooth L & 68.50 & 72.50 & 81.00 & & Tooth A & 1.60 & 0.50 & -0.60 \\
\hline & Tooth A & 4.30 & 3.00 & 1.60 & & Tooth B & 25.30 & 21.90 & 17.90 \\
\hline & Tooth B & 41.20 & 38.20 & 37.20 & 8 & Comp L & 75.50 & 75.50 & 82.80 \\
\hline \multirow[t]{6}{*}{2} & Comp L & 84.00 & 88.20 & 90.20 & & Comp A & -0.60 & -0.30 & -1.40 \\
\hline & Comp A & -2.80 & -2.90 & -2.90 & & Comp B & 18.00 & 22.30 & 22.40 \\
\hline & Comp B & 17.40 & 16.90 & 15.50 & & Tooth L & 77.80 & 76.40 & 83.60 \\
\hline & Tooth L & 74.90 & 80.60 & 86.40 & & Tooth A & -0.40 & -1.00 & -1.40 \\
\hline & Tooth A & -0.20 & -1.10 & -2.40 & & Tooth B & 23.20 & 23.90 & 22.90 \\
\hline & Tooth B & 20.00 & 19.20 & 18.10 & 9 & Comp L & 72.90 & 73.80 & 79.30 \\
\hline \multirow[t]{6}{*}{3} & Comp L & 75.60 & 84.40 & 86.90 & & Comp A & 4.80 & 4.60 & 4.20 \\
\hline & Comp A & 5.70 & 2.00 & 1.20 & & Comp B & 14.90 & 18.50 & 18.30 \\
\hline & Comp B & 32.60 & 22.10 & 27.70 & & Tooth L & 75.90 & 80.50 & 84.70 \\
\hline & Tooth L & 80.00 & 82.50 & 88.00 & & Tooth A & 3.00 & 1.20 & -0.60 \\
\hline & Tooth A & 3.00 & 1.30 & 0.60 & & Tooth B & 23.90 & 18.10 & 15.30 \\
\hline & Tooth B & 25.10 & 21.00 & 26.90 & 10 & Comp L & 80.90 & 84.90 & 92.10 \\
\hline \multirow[t]{6}{*}{4} & Comp L & 70.60 & 71.60 & 77.10 & & Comp A & -1.20 & -2.00 & -2.40 \\
\hline & Comp A & 1.50 & 1.70 & 0.40 & & Comp B & 24.00 & 22.80 & 22.10 \\
\hline & Comp B & 17.30 & 21.00 & 16.90 & & Tooth L & 81.30 & 83.50 & 89.50 \\
\hline & Tooth L & 65.20 & 71.40 & 76.50 & & Tooth A & 0.00 & -0.90 & 0.10 \\
\hline & Tooth A & 11.00 & -1.20 & -1.90 & & Tooth B & 22.60 & 20.10 & 21.00 \\
\hline & Tooth B & 22.50 & 19.60 & 17.50 & 11 & Comp L & 82.90 & 87.10 & 95.10 \\
\hline \multirow[t]{6}{*}{5} & Comp L & 80.90 & 86.00 & 89.40 & & Comp A & -1.50 & -1.20 & -2.00 \\
\hline & Comp A & -1.40 & -1.90 & -1.20 & & Comp B & 24.70 & 27.30 & 23.60 \\
\hline & Comp B & 17.00 & 18.80 & 20.50 & & Tooth L & 81.00 & 83.10 & 92.40 \\
\hline & Tooth L & 77.40 & 84.10 & 85.70 & & Tooth A & 1.30 & -0.40 & -0.80 \\
\hline & Tooth A & 0.80 & -1.30 & 0.30 & & Tooth B & 32.60 & 26.60 & 26.90 \\
\hline & Tooth B & 26.20 & 23.20 & 24.00 & 12 & Comp L & 62.20 & 67.10 & 67.40 \\
\hline \multirow[t]{6}{*}{6} & Comp L & 80.90 & 81.90 & 88.60 & & Comp A & 10.40 & 8.30 & 8.40 \\
\hline & Comp A & 1.80 & 2.00 & 1.60 & & Comp B & 24.10 & 21.80 & 23.50 \\
\hline & Comp B & 25.00 & 29.40 & 25.70 & & Tooth L & 70.90 & 74.90 & 74.20 \\
\hline & Tooth L & 76.00 & 81.00 & 84.00 & & Tooth A & 3.70 & 2.30 & 3.40 \\
\hline & Tooth A & 2.10 & 0.10 & 0.00 & & Tooth B & 24.10 & 18.70 & 18.40 \\
\hline & Tooth B & 31.10 & 29.70 & 29.90 & & & & & \\
\hline
\end{tabular}




\begin{tabular}{|c|c|c|c|c|c|c|c|c|c|}
\hline Tooth & Site & $\begin{array}{c}\text { No } \\
\text { treatment }\end{array}$ & $\begin{array}{c}5 \\
\text { Treatments }\end{array}$ & $\begin{array}{c}10 \\
\text { Treatments }\end{array}$ & 20 & Comp L & 81.00 & 84.00 & 86.10 \\
\hline \multirow[t]{6}{*}{13} & Comp L & 81.70 & 86.70 & 95.60 & & Comp A & -1.80 & -1.70 & -2.10 \\
\hline & Comp A & -0.50 & -1.30 & -1.90 & & Comp B & 16.00 & 18.90 & 17.10 \\
\hline & Comp B & 24.50 & 21.40 & 21.50 & & Tooth L & 80.20 & 79.30 & 83.00 \\
\hline & Tooth L & 77.00 & 78.10 & 86.60 & & Tooth A & 0.40 & 0.80 & -2.00 \\
\hline & Tooth A & 1.90 & 0.40 & -0.20 & & Tooth B & 25.90 & 26.30 & 23.70 \\
\hline & Tooth B & 30.40 & 28.60 & 24.50 & 21 & Comp L & 80.60 & 80.50 & 86.00 \\
\hline \multirow[t]{6}{*}{14} & Comp L & 80.20 & 81.10 & 82.00 & & Comp A & -0.10 & -0.40 & -1.10 \\
\hline & Comp A & -0.30 & -0.60 & -0.80 & & Comp B & 21.70 & 19.50 & 26.40 \\
\hline & Comp B & 21.00 & 20.60 & 22.20 & & Tooth L & 76.10 & 75.10 & 78.50 \\
\hline & Tooth L & 80.50 & 78.30 & 87.90 & & Tooth A & 2.20 & 0.70 & -0.10 \\
\hline & Tooth A & 0.10 & -0.40 & -1.30 & & Tooth B & 25.10 & 23.20 & 22.70 \\
\hline & Tooth B & 18.80 & 19.70 & 18.50 & 22 & Comp L & 77.20 & 84.20 & 86.60 \\
\hline \multirow[t]{6}{*}{15} & Comp L & 79.00 & 80.40 & 82.00 & & Comp A & 2.90 & 0.00 & 1.90 \\
\hline & Comp A & -1.00 & -1.40 & -1.90 & & Comp B & 29.90 & 25.60 & 38.30 \\
\hline & Comp B & 22.00 & 23.10 & 24.80 & & Tooth L & 73.40 & 73.30 & 79.10 \\
\hline & Tooth L & 73.00 & 77.80 & 82.40 & & Tooth A & 4.70 & 2.00 & -1.80 \\
\hline & Tooth A & 1.70 & -0.50 & -0.90 & & Tooth B & 34.30 & 31.30 & 27.00 \\
\hline & Tooth B & 26.60 & 26.90 & 29.50 & 23 & Comp L & 80.10 & 81.60 & 83.50 \\
\hline \multirow[t]{6}{*}{16} & Comp L & 85.00 & 89.40 & 87.40 & & Comp A & -1.10 & -1.20 & -1.90 \\
\hline & Comp A & -0.10 & -2.30 & -2.00 & & Comp B & 15.80 & 17.00 & 13.10 \\
\hline & Comp B & 28.70 & 20.00 & 22.60 & & Tooth L & 62.20 & 68.00 & 69.30 \\
\hline & Tooth L & 81.30 & 81.20 & 93.60 & & Tooth A & 3.20 & 1.50 & -0.40 \\
\hline & Tooth A & 1.60 & -0.90 & -1.30 & & Tooth B & 21.50 & 19.20 & 15.20 \\
\hline & Tooth B & 28.40 & 22.40 & 23.90 & 24 & Comp L & 87.90 & 89.10 & 90.30 \\
\hline \multirow[t]{6}{*}{17} & Comp L & 85.20 & 88.60 & 87.80 & & Comp A & -0.90 & -1.20 & -2.10 \\
\hline & Comp A & -1.30 & -1.50 & -2.30 & & Comp B & 19.40 & 17.40 & 21.50 \\
\hline & Comp B & 21.80 & 24.80 & 17.60 & & Tooth L & 80.30 & 70.80 & 85.60 \\
\hline & Tooth L & 80.60 & 80.50 & 87.40 & & Tooth A & 4.00 & 2.60 & -1.00 \\
\hline & Tooth A & 0.10 & -0.40 & -2.00 & & Tooth B & 36.00 & 29.00 & 33.90 \\
\hline & Tooth B & 23.20 & 22.60 & 18.80 & 25 & Comp L & 89.20 & 85.20 & 98.50 \\
\hline \multirow[t]{6}{*}{18} & Comp L & 85.30 & 92.70 & 93.50 & & Comp A & -2.50 & -2.50 & -3.80 \\
\hline & Comp A & -2.30 & -2.60 & -3.30 & & Comp B & 16.30 & 17.40 & 15.30 \\
\hline & Comp B & 18.20 & 17.40 & 20.30 & & Tooth L & 84.60 & 89.60 & 98.10 \\
\hline & Tooth L & 85.70 & 85.90 & 96.90 & & Tooth A & -0.70 & -2.00 & -3.60 \\
\hline & Tooth A & -0.90 & -1.50 & -2.50 & & Tooth B & 20.90 & 16.00 & 14.70 \\
\hline & Tooth B & 20.80 & 17.30 & 18.10 & \multicolumn{5}{|c|}{$\begin{array}{l}\text { Table } 1-L, A \text { and } B \text { values for compositeanc } \\
\text { samples at } 0,5 \text { and } 10 \text { treatments }\end{array}$} \\
\hline \multirow[t]{6}{*}{19} & Comp L & 78.00 & 82.80 & 83.80 & & & & & \\
\hline & Comp A & -2.20 & -2.30 & -2.50 & & & & & \\
\hline & Comp B & 18.30 & 18.60 & 17.40 & & & & & \\
\hline & Tooth L & 78.10 & 79.00 & 83.20 & & & & & \\
\hline & Tooth A & -0.20 & -0.60 & -1.10 & & & & & \\
\hline & Tooth B & 24.60 & 22.10 & 21.20 & & & & & \\
\hline
\end{tabular}




\begin{tabular}{|c|c|c|}
\hline Tooth & $\begin{array}{c}\Delta \mathrm{E} 0 \text { to } 5 \\
\text { Treatments } \\
\text { Composite }\end{array}$ & $\begin{array}{c}\Delta \mathrm{E} 0 \text { to } 5 \\
\text { Treatments } \\
\text { Tooth } \\
\end{array}$ \\
\hline 1 & 2.75 & 5.66 \\
\hline 2 & 4.23 & 6.60 \\
\hline 3 & 14.19 & 5.09 \\
\hline 4 & 3.84 & 13.99 \\
\hline 5 & 5.43 & 7.64 \\
\hline 6 & 4.52 & 5.56 \\
\hline 7 & 3.66 & 6.39 \\
\hline 8 & 4.31 & 1.68 \\
\hline 9 & 3.72 & 7.62 \\
\hline 10 & 4.25 & 3.45 \\
\hline 11 & 4.95 & 6.58 \\
\hline 12 & 5.81 & 6.86 \\
\hline 13 & 5.94 & 2.43 \\
\hline 14 & 1.03 & 2.43 \\
\hline 15 & 1.82 & 5.29 \\
\hline 16 & 9.99 & 6.50 \\
\hline 17 & 4.54 & 0.79 \\
\hline 18 & 7.45 & 3.56 \\
\hline 19 & 4.81 & 2.69 \\
\hline 20 & 4.17 & 1.06 \\
\hline 21 & 2.22 & 2.62 \\
\hline 22 & 8.71 & 4.04 \\
\hline 23 & 1.92 & 6.47 \\
\hline 24 & 2.35 & 11.88 \\
\hline 25 & 4.15 & 7.12 \\
\hline
\end{tabular}

Table 2 - $\Delta E$ of the resin composite and the natural tooth from 0 to 5 treatments 


\begin{tabular}{|c|c|c|}
\hline Tooth & $\begin{array}{l}\Delta \mathrm{E} 0 \text { to } 10 \\
\text { Treatments } \\
\text { Composite }\end{array}$ & $\begin{array}{c}\Delta \mathrm{E} 0 \text { to } 10 \\
\text { Treatments } \\
\text { Tooth }\end{array}$ \\
\hline 1 & 5.77 & 13.23 \\
\hline 2 & 6.49 & 11.86 \\
\hline 3 & 13.11 & 8.54 \\
\hline 4 & 6.60 & 17.86 \\
\hline 5 & 9.19 & 8.60 \\
\hline 6 & 7.73 & 8.36 \\
\hline 7 & 6.17 & 10.62 \\
\hline 8 & 8.56 & 5.89 \\
\hline 9 & 7.27 & 12.82 \\
\hline 10 & 11.42 & 8.36 \\
\hline 11 & 12.26 & 12.92 \\
\hline 12 & 5.60 & 6.59 \\
\hline 13 & 14.29 & 11.46 \\
\hline 14 & 2.22 & 7.54 \\
\hline 15 & 4.20 & 10.17 \\
\hline 16 & 6.82 & 13.41 \\
\hline 17 & 5.04 & 8.37 \\
\hline 18 & 8.52 & 11.63 \\
\hline 19 & 5.88 & 6.20 \\
\hline 20 & 5.23 & 4.29 \\
\hline 21 & 7.23 & 4.10 \\
\hline 22 & 12.65 & 11.32 \\
\hline 23 & 4.41 & 10.15 \\
\hline 24 & 3.41 & 7.58 \\
\hline 25 & 9.44 & 15.14 \\
\hline
\end{tabular}

Table 3 - $\Delta E$ of the resin composite and the natural tooth from 0 to 10 treatments 


\begin{tabular}{|c|c|c|c|}
\hline Tooth & $\begin{array}{c}\text { Delta } \mathrm{E} \text { at } \\
0 \text { treatments }\end{array}$ & $\begin{array}{c}\text { Delta E at } \\
5 \text { treatments }\end{array}$ & $\begin{array}{c}\text { Delta } E \text { at } \\
10 \\
\text { treatments }\end{array}$ \\
\hline 1 & 26.95 & 24.55 & 21.77 \\
\hline 2 & 9.81 & 8.14 & 4.63 \\
\hline 3 & 9.10 & 2.30 & 1.49 \\
\hline 4 & 12.10 & 3.23 & 2.45 \\
\hline 5 & 10.09 & 4.83 & 5.31 \\
\hline 6 & 7.83 & 2.12 & 6.43 \\
\hline 7 & 11.46 & 7.53 & 5.15 \\
\hline 8 & 5.69 & 1.96 & 0.94 \\
\hline 9 & 9.66 & 7.52 & 7.82 \\
\hline 10 & 1.89 & 3.23 & 3.77 \\
\hline 11 & 8.59 & 4.14 & 4.43 \\
\hline 12 & 10.98 & 10.32 & 9.86 \\
\hline 13 & 7.92 & 11.34 & 9.64 \\
\hline 14 & 2.26 & 2.95 & 6.98 \\
\hline 15 & 8.03 & 4.69 & 4.82 \\
\hline 16 & 4.08 & 8.66 & 6.37 \\
\hline 17 & 5.01 & 8.47 & 1.30 \\
\hline 18 & 2.98 & 6.89 & 4.13 \\
\hline 19 & 6.61 & 5.44 & 4.09 \\
\hline 20 & 10.17 & 9.12 & 7.29 \\
\hline 21 & 6.09 & 6.64 & 8.42 \\
\hline 22 & 6.09 & 12.46 & 14.06 \\
\hline 23 & 19.27 & 14.04 & 14.43 \\
\hline 24 & 18.90 & 22.00 & 13.31 \\
\hline 25 & 6.75 & 4.64 & 0.75 \\
\hline Mean & 9.13 & 7.89 & 6.79 \\
\hline
\end{tabular}




\begin{tabular}{|c|c|c|c|c|c|c|}
\hline Tooth & $\begin{array}{c}\text { Tooth - } 0 \\
\text { Treatments }\end{array}$ & $\begin{array}{c}\text { Composite - } 0 \\
\text { Treatments }\end{array}$ & $\begin{array}{c}\text { Tooth - } 5 \\
\text { Treatments }\end{array}$ & $\begin{array}{l}\text { Composite - } 5 \\
\text { Treatments }\end{array}$ & $\begin{array}{l}\text { Tooth - } 10 \\
\text { Treatments }\end{array}$ & $\begin{array}{c}\text { Composite - } 10 \\
\text { Treatments }\end{array}$ \\
\hline 1 & A4 & $\mathrm{A} 2$ & A3.5 & $\mathrm{A} 2$ & B2 & B2 \\
\hline 2 & A3 & B2 & A3 & $\mathrm{A} 2$ & B1 & B2 \\
\hline 3 & B4 & A4 & $\mathrm{A} 2$ & $\mathrm{~A} 2$ & $\mathrm{~A} 1$ & A3 \\
\hline 4 & A4 & A3 & A3.5 & $\mathrm{C} 1$ & B2 & B2 \\
\hline 5 & B3 & B2 & A3.5 & B2 & $\mathrm{A} 1$ & B2 \\
\hline 6 & A3.5 & B3 & B3 & B2 & $\mathrm{A} 2$ & B2 \\
\hline 7 & B4 & $\mathrm{C} 1$ & B3 & B2 & $\mathrm{A} 3$ & A3 \\
\hline 8 & B3 & $\mathrm{A} 2$ & B3 & A3 & $\mathrm{A} 2$ & A3 \\
\hline 9 & B3 & C1 & $\mathrm{A} 2$ & $\mathrm{C} 2$ & $\mathrm{~A} 1$ & $\mathrm{C} 2$ \\
\hline 10 & $\mathrm{~A} 2$ & A3 & B2 & $\mathrm{A} 2$ & B1 & $\mathrm{A} 2$ \\
\hline 11 & A3.5 & A3 & A3.5 & A3 & $\mathrm{A} 1$ & A3 \\
\hline 12 & A4 & $\mathrm{C} 4$ & A3.5 & $\mathrm{C} 2$ & $\mathrm{C} 2$ & $\mathrm{C} 1$ \\
\hline 13 & A3.5 & $\mathrm{A} 2$ & B3 & $\mathrm{C} 2$ & B1 & B2 \\
\hline 14 & $\mathrm{~A} 2$ & $\mathrm{~A} 2$ & $\mathrm{~A} 2$ & $\mathrm{~A} 2$ & B1 & A1 \\
\hline 15 & A3.5 & A3 & B3 & B3 & $\mathrm{A} 2$ & A3 \\
\hline 16 & B3 & B3 & B2 & B3 & B1 & B2 \\
\hline 17 & A2 & B2 & $\mathrm{A} 2$ & $\mathrm{~A} 2$ & A1 & $\mathrm{A} 1$ \\
\hline 18 & B2 & B2 & A1 & B2 & B1 & B1 \\
\hline 19 & B3 & B2 & $\mathrm{A} 2$ & B3 & B1 & $\mathrm{A} 1$ \\
\hline 20 & B3 & B2 & B3 & $\mathrm{A} 2$ & $\mathrm{~A} 1$ & $\mathrm{~A} 2$ \\
\hline 21 & B3 & $\mathrm{A} 2$ & B3 & $\mathrm{A} 2$ & $\mathrm{~A} 2$ & A3 \\
\hline 22 & A4 & A3. 5 & A3.5 & $\mathrm{A} 2$ & B2 & $\mathrm{A} 2$ \\
\hline 23 & A4 & $\mathrm{A} 3$ & $\mathrm{C} 2$ & $\mathrm{C} 2$ & $\mathrm{C} 1$ & $\mathrm{~A} 2$ \\
\hline 24 & A3.5 & $\mathrm{C} 1$ & A1 & $\mathrm{A} 2$ & $\mathrm{~A} 1$ & B2 \\
\hline 25 & $\mathrm{~A} 2$ & $\mathrm{~A} 1$ & B1 & $\mathrm{A} 2$ & B1 & B1 \\
\hline
\end{tabular}




\begin{tabular}{|c|c|c|c|c|}
\hline Tooth & $\begin{array}{c}\text { Shade tab change from } 0 \text { to } \\
5 \text { treatments - Tooth }\end{array}$ & $\begin{array}{c}\text { Shade tab change from } 0 \text { to } 5 \\
\text { treatments - composite }\end{array}$ & $\begin{array}{c}\text { Shade tab change from } 0 \text { to } \\
10 \text { treatments - Tooth }\end{array}$ & $\begin{array}{c}\text { Shade tab change from } 0 \text { to } 10 \\
\text { treatments - Composite }\end{array}$ \\
\hline 1 & 3 & 0 & 12 & 2 \\
\hline 2 & 0 & -2 & 8 & 0 \\
\hline 3 & 8 & 10 & 11 & 10 \\
\hline 4 & 3 & 3 & 12 & 6 \\
\hline 5 & -1 & 0 & 9 & 0 \\
\hline 6 & 1 & 8 & 7 & 8 \\
\hline 7 & 2 & 3 & 4 & 3 \\
\hline 8 & 0 & -4 & 6 & -4 \\
\hline 9 & 6 & -1 & 9 & -1 \\
\hline 10 & 2 & 4 & 4 & 4 \\
\hline 11 & 0 & 0 & 10 & 0 \\
\hline 12 & 3 & 9 & 8 & 10 \\
\hline 13 & 1 & -2 & 11 & 2 \\
\hline 14 & 0 & 0 & 4 & 3 \\
\hline 15 & 1 & -2 & 7 & 0 \\
\hline 16 & 8 & 0 & 10 & 8 \\
\hline 17 & 0 & -2 & 3 & 1 \\
\hline 18 & 1 & 0 & 2 & 2 \\
\hline 19 & 6 & 0 & 10 & 1 \\
\hline 20 & 0 & -2 & 9 & -2 \\
\hline 21 & 0 & 0 & 6 & -4 \\
\hline 22 & 3 & 7 & 12 & 7 \\
\hline 23 & 8 & 2 & 9 & 4 \\
\hline 24 & 10 & 1 & 10 & 2 \\
\hline 25 & 4 & -3 & 4 & 1 \\
\hline Mean & 2.8 & 1.2 & 7.9 & 2.5 \\
\hline
\end{tabular}

Table 6 - Number of shades a tooth or composite sample changed when ordered by decreasing value - VITA classical (negative numbers represent a decrease in value) 
All data obtained through use of the VITA Easyshade 4.0 is shown in Table 1. Data from

Table 1 was used to calculate the $\Delta \mathrm{E}$ value of the tooth or composite from 0 to 5 bleaching treatments (Table 2 ) and the $\Delta \mathrm{E}$ value of the tooth or composite from 0 to 10 bleaching treatments (Table 3 ) when compared to time zero. The average $\Delta \mathrm{E}$ of the composite at 0 treatments and the composite at 5 treatments was 4.83 while the $\Delta \mathrm{E}$ of the tooth at this same 0 to 5 treatment interval was 5.31. A p-value of 0.2934 was found and thus, not statistically significant. For 0 to 10 treatments, the average $\Delta \mathrm{E}$ of the composite was 7.58 while the mean for the $\Delta E$ of the tooth was 9.88. A paired t- test yielded a $p$-value of 0.0048 between these treatment variables.

Table 4 shows the $\Delta \mathrm{E}$ of the tooth and the composite for each tested tooth at treatment intervals of 0,5 and 10 . The average $\Delta \mathrm{E}$ for the tooth and adjacent composite at 0 treatments was 9.13. The average $\Delta \mathrm{E}$ for the tooth and adjacent composite at 5 treatments was 7.89 . The average $\Delta \mathrm{E}$ for the tooth and adjacent composite at 10 treatments was 6.79. A paired t-test of data sets of $\Delta E$ from 0 and 5 treatments failed to demonstrate a statistically significant difference $(p=0.0625)$. A paired t-test comparing the difference between tooth and composite of $\Delta E$ from 0 and 10 treatments yielded a statistically significant difference $(p=0.0045)$. ANOVA, in which $\Delta \mathrm{E}$ was the outcome, was completed and the factor of interest (number of treatments) was statistically significant with a p-value of 0.0023 .

The shades from the VITA classic shade guide were given a numerical value from 1-16. The shade with the highest value, B1, was given a numerical value of 1 and the shade with the lowest value, C4, was given 16 . The order is as follows: 
$B 1, A 1, B 2, D 2, A 2, C 1, C 2, D 4, A 3, D 3, B 3, A 3.5, B 4, C 3, A 4, C 4$

Table 5 shows the selected visual shade for each tooth and composite sample at each treatment interval. Table 6 shows the number of shade-tab changes of each tooth and composite sample tested at 5 and 10 treatments. The average number of shades the tooth changed from 0 to 5 treatments was 2.76 and was 1.16 for the composite from 0 to 5 treatments; the two values were significantly different ( $p$-value $=0.0336)$. The average number of shades the tooth changed from 0 to 10 treatments was 7.88 and was 2.52 for the composite from 0 to 10 treatments; the two values were significantly different ( $p$-value $\left.=3.56 \times 10^{\wedge}-7\right)$. 


\section{Chapter V - Discussion}

The purpose of this investigation was to evaluate if OMNiCHROMA resin composite would change shade with a tooth, when external bleaching was performed. This was measured both visually and with the use of a colorimeter. When evaluated with the colorimeter, a significant decrease in $\Delta \mathrm{E}$ of the tooth to the composite was found when comparing 0 and 10 bleaching treatments, demonstrating that as the bleaching was performed the color match between composite and tooth improved. Our study though did demonstrate that there may be a certain threshold of minimum treatments required to have this effect as the difference was not seen when comparing 0 to 5 bleaching treatments. This finding supports the notion that when using OMNiCHROMA resin composite, the discernable difference between the composite and the natural tooth decreases as bleaching with $15 \%$ opalescence progresses from 0 to 5 treatments but becomes significant from 5 to 10 treatments.

Calculating $\Delta \mathrm{E}$ using a colorimeter allowed for a non-subjective quantification and analysis of data. As mentioned previously, the $\Delta \mathrm{E}$ of the composite and tooth at 0,5 and 10 treatments were $9.13,7.89$ and 6.79 respectively. This progressive decrease in $\Delta \mathrm{E}$ from 0 to 10 treatments demonstrates the ability of this particular resin composite to change shade, allowing a patient to proceed with external bleaching while decreasing the likelihood of a perceptible difference in shade of the composite and the newly whitened tooth structure. As stated before, a $\Delta E$ of 1.2 is known as the $50: 50 \%$ perceptibility threshold where $50 \%$ of skilled clinicians are unable to predictably detect a color difference. From collected data, the $\Delta E$ from 0 
to 10 treatments decreased by an average of 6.79 but the resulting $\Delta \mathrm{E}$ average is still above 1.2 . Interestingly though this is similar to findings of other studies where $\Delta \mathrm{E}$ values of tooth and restorative material were analyzed ((Li, Yu and Wang 2009) and (Hof et al. 2018)). Thus, it is reasonable to assume that a skilled clinician would have the ability to discern the composite from the adjacent tooth structure based on color alone. However, there are numerous other factors that help a direct composite restoration to blend harmoniously with the surrounding dentition, such as surface texture, contours of the restoration, preparation design (bevel vs scalloped bevel), and size of the caries and resulting preparation (Samorodnitzky-Naveh et al. 2010). If these other factors that yield a highly successful composite restoration are executed well, the ability of the composite restoration to appear whiter than the surrounding tooth provide enough of a buffer to allow the restoration to remain without issue. A similarly contoured composite without this color matching capability could need to be replaced. The $\Delta \mathrm{E}$ value obtained and the strength of the significance found in this study could lead further investigation into whether different types of tooth whitening treatment options produce similar or potentially better results. Hypothesis 3 stated that there will be a significant difference in the $\Delta \mathrm{E}$ of the resin composite and the surrounding tooth structure as bleaching treatment increases from 0 to 10 treatments. This hypothesis was found to be true within the limits of this study.

When using the VITA Easyshade 4.0 to analyze each variable at each time interval, it was noted that at both 5 and 10 treatment intervals, the treated tooth had a higher $\Delta \mathrm{E}$ than the composite. The results were statistically significant at both treatment intervals. This means that the tooth itself bleached more effectively than the composite did and that the rate at which the 
tooth becomes brighter was not proportional to the rate at which the composite appears brighter. No data obtained in this study provides an explanation for these findings. Consideration of the mechanism by which tooth bleaching operates could provide a possible explanation of the data obtained in this study. The lack of hydroxyapatite crystals for the active peroxide agent to interact with within the composite could mean that the tooth is actively being whitened while the resulting color change in the composite is due to the surrounding color change of the enamel/dentin. There is no evidence present to state that the carbamide peroxide gel can whiten the composite itself. Hypothesis 2 stated that when using a colorimeter, there will be a significant difference in the shade of resin composite before and after bleaching. This hypothesis was found to be true within the limits of this study.

A popular method of arranging the VITA shade guide is by value. For this study, the shade guide was arranged by value starting with B1 at the highest value and transitioned to shades of lower value with $\mathrm{C} 4$ being the lowest. Each shade tab was given a numerical value ranging from 1 to 16 ( $B 1=1$ and $C 4=16$ ) in order to determine how many shades a tooth or composite changed throughout this study. It was noted that the mean change in shade for the composite from 0 to 10 treatments was 2.5 while the mean change for the tooth at the same treatment interval was 7.9. These results were significantly different. Simply put, the tooth structure itself increases in value more than the composite does over the same treatment interval. This data is congruent to the data generated with the Easyshade. The mean change in shade for the composite from 0 to 5 treatments was 1.2 shades while the mean change for the tooth was 2.8. These two values were not significantly different. When measuring the shade visually and comparing the results to those obtained with the Easyshade, it was found that both 
methods showed results of the natural tooth structure becoming whiter than the composite. Hypothesis 1 stated, when using a visual shade guide, there will be a significant difference in the perceived shade of resin composite before and after bleaching. This hypothesis was found to be true within the limits of this study.

With the findings from this study, there are areas of future research that could be further investigated. Firstly, more extensive investigation of the use of various whitening regimens could be explored. Only one type of whitening regimen was examined here but this type of study could be done with in-office bleaching treatment or over the counter whitening strips. The same type of investigation could then be compared side by side to determine all results obtained. Additionally, this investigation only looked into one concentration of at-home bleaching agent, $15 \%$. Concentrations can vary from $10 \%, 15 \%, 20 \%$ and $35 \%$. As more whitening modalities are investigated, the information could increase the significance of findings obtained in this study. Secondly, it would be beneficial to study the effects of bleaching on OMNiCHROMA composite in vivo. Efforts could be made to mimic intraoral conditions as much as possible but will fall short of comprehensively simulating all conditions and more relevant information could be gathered by performing this study in vivo. Thirdly, it could be beneficial to evaluate the long-term effects of this type of study. A limitation of this study is that it does not consider the process of tooth discoloration and long-term stability of the composite material itself. 


\section{Summary and Conclusion}

\section{Summary}

The present study investigated the visual and spectrophotometric color change $(\Delta \mathrm{E})$ between natural tooth and OMNiCHROMA resin composite when 15\% Carbamide peroxide gel was applied for 10 treatments. The tooth and the composite both became brighter in appearance from 0 treatments to 10 treatments. As the whitening treatments progressed from 0 to 10 , the $\Delta \mathrm{E}$ decreased; the shade difference between the tooth and adjacent composite decreased and became more difficult to differentiate. When evaluated visually, the tooth appeared to change color significantly more than the composite itself. These findings are novel and warrant further investigation with other tooth whitening modalities.

\section{Conclusion}

1. Natural tooth structure bleaches more effectively than OMNiCHROMA composite at 10 treatments of $15 \%$ carbamide peroxide.

2. When measured visually and spectrophotometrically, OMNiCHROMA resin composite demonstrated the ability to change shade after surrounding tooth structure was bleached.

3. Additional investigation of other bleaching treatment modalities and the effectiveness is warranted. 


\section{Works cited}

(2017) The Glossary of Prosthodontic Terms: Ninth Edition. J Prosthet Dent, 117, e1-e105.

Baroudi, K. \& N. A. Hassan (2014) The effect of light-activation sources on tooth bleaching. Niger Med J, $55,363-8$.

Braun, A., S. Jepsen \& F. Krause (2007) Spectrophotometric and visual evaluation of vital tooth bleaching employing different carbamide peroxide concentrations. Dent Mater, 23, 165-9.

Cochrane, S. (2014) The Munsell Color System: a scientific compromise from the world of art. Stud Hist Philos Sci, 47, 26-41.

Dietschi, D., N. Benbachir \& I. Krejci (2010) In vitro colorimetric evaluation of the efficacy of home bleaching and over-the-counter bleaching products. Quintessence Int, 41, 505-16.

Hayward, R., Y. Osman \& S. R. Grobler (2012) A clinical study of the effectiveness of a light emitting diode system on tooth bleaching. Open Dent J, 6, 143-7.

Hof, M., N. Umar, N. Budas, R. Seemann, B. Pommer \& W. Zechner (2018) Evaluation of implant esthetics using eight objective indices-Comparative analysis of reliability and validity. Clin Oral Implants Res, 29, 697-706.

Howard, B., N. D. Wilson, S. M. Newman, C. S. Pfeifer \& J. W. Stansbury (2010) Relationships between conversion, temperature and optical properties during composite photopolymerization. Acta Biomater, 6, 2053-9.

Ilie, N. \& G. Furtos (2020) A Comparative Study of Light Transmission by Various Dental Restorative Materials and the Tooth Structure. Oper Dent.

Ilie, N. \& R. Hickel (2011) Resin composite restorative materials. Aust Dent J, 56 Suppl 1, 59-66. Joiner, A. \& W. Luo (2017) Tooth colour and whiteness: A review. J Dent, 67S, S3-S10.

Kim-Pusateri, S., J. D. Brewer, E. L. Davis \& A. G. Wee (2009) Reliability and accuracy of four dental shade-matching devices. J Prosthet Dent, 101, 193-9. 
Kuehni, R. \& R. Marcus. 1979. An Experiment in Visual Scaling of Small Color Differences. 83-91. COLOR Research and Application

Kuehni, R. G. (1976) Color-tolerance data and the tentative CIE $1976 \mathrm{~L}$ a b formula. J Opt Soc Am, 66, 497-500.

Li, Q., H. Yu \& Y. N. Wang (2009) Spectrophotometric evaluation of the optical influence of core build-up composites on all-ceramic materials. Dent Mater, 25, 158-65.

Pereira Sanchez, N., J. M. Powers \& R. D. Paravina (2019) Instrumental and visual evaluation of the color adjustment potential of resin composites. J Esthet Restor Dent, 31, 465-470.

Revilla-León, M., P. Jiang, M. Sadeghpour, W. Piedra-Cascón, A. Zandinejad, M. Özcan \& V. R. Krishnamurthy (2019) Intraoral digital scans-Part 1: Influence of ambient scanning light conditions on the accuracy (trueness and precision) of different intraoral scanners. J Prosthet Dent.

Samorodnitzky-Naveh, G. R., Y. Grossman, Y. G. Bachner \& L. Levin (2010) Patients' self-perception of tooth shade in relation to professionally objective evaluation. Quintessence Int, 41, e80-3.

Soeteman, G. D., C. Valkenburg, G. A. Van der Weijden, C. Van Loveren, E. Bakker \& D. E. Slot (2018) Whitening dentifrice and tooth surface discoloration-a systematic review and meta-analysis. Int J Dent Hyg, 16, 24-35.

Suh, Y. R., J. S. Ahn, S. W. Ju \& K. M. Kim (2017) Influences of filler content and size on the color adjustment potential of nonlayered resin composites. Dent Mater J, 36, 35-40.

Sun, L., S. Liang, Y. Sa, Z. Wang, X. Ma, T. Jiang \& Y. Wang (2011) Surface alteration of human tooth enamel subjected to acidic and neutral 30\% hydrogen peroxide. J Dent, 39, 686-92.

Tabatabaian, F. (2019) Color Aspect of Monolithic Zirconia Restorations: A Review of the Literature. J Prosthodont, 28, 276-287. 
Tam, L. E., N. Kim \& G. M. De Souza (2017) Effect of tooth whitening strips on fatigue resistance and flexural strength of bovine dentin in vitro. PLoS One, 12, e0173480.

Trifkovic, B., J. M. Powers \& R. D. Paravina (2018) Color adjustment potential of resin composites. Clin Oral Investig, 22, 1601-1607.

Vanderburgt, T. (1990) A comparison of new and conventional methods for quantification of tooth color. The Journal of Prosthetic Dentistry, 63, 155-162.

Vichi, A., C. Louca, G. Corciolani \& M. Ferrari (2011) Color related to ceramic and zirconia restorations: a review. Dent Mater, 27, 97-108.

Çetin, C. \& C. K. Erdal Eroğlu, Özlem Özişçi (2019) CIE L*a*b* Color Analyses of Anterior Maxillary Teeth According to Gender and Localization Variables. SDU Journal of Health Science Institute, 10, 448 - 453. 